The Edinburgh Poisoning Treatment Centre is a selfcontained unit of 20 beds serving a catchment area of 500,000 population. This is twice as large a population as the average accident and emergency department serves. Though Matthew and his colleagues place great importance on the fact that their unit is self-contained, this appears to be much more difficult to justify when there are only half this number of beds. It is much more likely in the district general hospitals that the unconscious patients will first be admitted to the intensive care units, especially as the principal treatment now is supportive. The conscious patients will probably be admitted firstly to the medical wards and then, if necessary, transferred rapidly to a short stay psychiatric unit, preferably within the same hospital. This pattern is similar to that recommended in the Hill report. The effect of increasing the catchment area in order to make a self-contained unit viable, and to justify the additional staff and equipment, would in many areas lead to a delay in the patient's arrival in hospital. Though there are no data on the effect of time and distance on the mortality rate, the excellent success rate in those patients who reach hospital alive is evidence enough not to make the centres too far apart.

There is, however, no doubt from this paper that the designation of a consultant in charge is an extremely important recommendation, which results in better co-ordination of the different branches of medicine that may be concerned in resuscitation and rehabilitation.

Since, therefore, it appears that virtually no additional resources are necessary to treat acute poisoning in district general hospitals with accident and emergency departments, the designation of a poisoning treatment centre need not be subject to the demands of other hospital services on available resources.

\section{Maintenance Haemodialysis}

The two years since our last leading article $^{1}$ on the management of end-stage renal failure has been a time of consolidation rather than of innovation in the field of maintenance haemodialysis. By March 1969 4,302 patients had started on treatment in Europe ${ }^{2}$ compared to 1,163 in 1967. The absence of a significant fall in mortality (32\% in 1967, $30.5 \%$ in 1969) is disappointing, but may in part be an effect of high mortality figures from newly opened units.

The excellent results which may be achieved in a wellequipped dialysis centre with experienced staff are shown by a recent report ${ }^{3}$ from $J$. R. Curtis and his colleagues. Their total experience was 41 patient-years ; 32 patients started on treatment and 3 died. Psychosocial rehabilitation is just as important a measure of successful dialysis as survival, and only four of their patients failed to resume useful employment. Though depression, anxiety, and frustration were common, no patient required psychiatric treatment.

Curtis and his colleagues also give a comprehensive account of the technical and medical difficulties of long-term haemodialysis. One of the most troublesome problems besetting patients and their medical attendants is the arteriovenous shunt. With scrupulous attention to detail a mean survival rate of 17.0 months for arterial cannulae and 9.6 months for venous cannulae was obtained. The incidence of clotting in the shunt was shown to be reduced by long-term treatment with anticoagulants. In many other units the survival of shunts is less satisfactory, and the use of a Brescia-Cimino fistula ${ }^{4}$ instead is increasing in popularity. An outbreak of hepatitis affected 15 patients (with one death) but no members of the staff. An incubation period of seven to nine weeks and modification of the course of the disease by gammaglobulin suggested that this was infectious hepatitis rather than serum hepatitis. Blood transfusion requirements were reduced from 2.5 units to 0.34 unit per patient-month by a policy of withholding transfusion until major symptoms of anaemia appeared. Renal osteodystrophy may progress in spite of otherwise adequate dialysis, ${ }^{5}$ and it is encouraging to note that Curtis and his colleagues found no evidence of progressive bone decalcification or metastatic calcification in their patients. A dialysate calcium concentration of $6 \mathrm{mg} . /$ $100 \mathrm{ml}$. appears to be critical ${ }^{6}{ }^{7}$; aluminium hydroxide was given when the calcium-phosphate product exceeded 75, and vitamin $\mathrm{D}$ was rarely used. One patient required parathyroidectomy. No patient developed peripheral neuropathy after starting dialysis, and pre-existing neuropathy regressed. Hypertension was controlled by dialysis and dietary salt restriction in all but two patients, in whom bilateral nephrectomy was eventually performed.

Clearly, haemodialysis can offer a worth-while life to many patients who would otherwise die of renal failure. In England and Wales some 600 patients are being treated at present, but every year over 2,000 prospective patients die. ${ }^{8}$ Selfdialysis by patients in their own homes ${ }^{9}$ reduces the pressure on hospital beds and staff, and it has the additional advantages of decreasing the patient's feeling of dependency and of a lower incidence of complications of dialysis. For these reasons most units in Britain are now concentrating on training for home dialysis, though not all patients are suitable, and indeed its difficulties may have been underrated. ${ }^{10}$ Patients dialysing themselves at home still require the support of a dialysis centre, so the number of patients that can be managed by any one unit is limited. When all the present and planned units in England and Wales are fully operational their maximum total complement is unlikely to exceed 3,000 patients. So with current resources only a minority of the patients who could benefit will receive treatment with maintenance haemodialysis.

The number of patients who have been treated by renal transplantation is as yet too small to have lessened the demand for dialysis to any extent. But a successful transplant is preferable to lifelong dialysis; and the results of transplan-

1 British Medical fournal, 1967, 1, 581.

Drukker, W., Haagsma-Schouten, W. A. G., Alberts, C., and Spoek, M. G., Proceedings of the European 'Dialysis and Transplant Association, 1969, 6, in press.

- Curtis, J. R., et al., Quarterly fournal of Medicine, 1969, 38, 49.

Brescia, M. J., Cimino, J. E., Appel, K., and Hurwich, B. J., New England fournal of Medicine, 1966, 275, 1089.

- Hampers, C. L., and Schupak, E., Long Term Hemodialysis, 1967, London, Heinemann.

Kaye, M., Mangel, R., and Neubauer, E., Proceedings of the European Dialysis and Transplant Association, 1966, 3, 17.

- Wing, A. J., British Medical fournal, 1968, 4, 145. 8 Kerr, D. N. S., Proceedings of the Royal Society of Medicine, 1967,
60, 1195.

- Baillod, R. A., Comty, C., Ilahi, M., Konotey-Ahulu, F. I. D., Sevitt, L., and Shaldon, S., Proceedings of the European Dialysis and Transplant Association, 1965, 2,99.

1 Smith, E. K. M., Curtis, J. R., McDonald, S. J., and de Wardener, H. E., Lancet, 1969, 1, 614.

1 Calne, R. Y., et al., British Medical fournal, 1968, 2, 404.

Marshall, V., Kincaid-Smith, P., Morris, P. J., Saker, B., and Eremin, J., Lancet, 1968, 2, 927.

1s Pletka, P., et al., Lancet, 1969, 1, 1. 14 Woodruff, M. F. A., Nolan, B., Robson, J. S., and MacDonald, M. K.,
Lancet, 1969, 1, 6. 
tation at present, with one-year survival rates ${ }^{11-14}$ for recipients of cadaveric grafts of $46 \%-75 \%$, are not far off the point when transplantation rather than dialysis may be considered to be the treatment of choice for end-stage renal failure. Further improvements in techniques such as tissue typing, immunosuppression, and preservation of donor organs may be expected, so though the problem of the provision of sufficient donor kidneys remains to be solved it will soon be time for the allocation of resources for a considerable expansion of facilities for renal transplantation. When transplantation becomes available on a large scale established haemodialysis centres will not be redundant. They will be required to maintain a pool of recipients awaiting grafts, to treat transplanted patients during episodes of acute tubular necrosis and after graft rejection, and for the permanent maintenance of patients who are unsuitable for transplantation because of diseases such as progressive glomerulonephritis or abnormalities of the lower urinary tract.

\section{Defensive Mechanisms of the Bladder}

The defensive mechanisms of the bladder play an important part in protecting the kidneys, since kidney infection is usually the result of ascending infection from the bladder. Women are particularly prone to invasion of the bladder by bowel organisms, owing to factors such as the shortness of the female urethra, the effects of sexual intercourse and improper cleansing of the perineum, and the use of napkins in childhood and sanitary towels in later life. It has also been shown that the urinary stream in women is turbulent, and that this may produce a reversal of the peripheral part of the stream, which could carry organisms from close to the meatus up into the bladder. ${ }^{1}$ Since human urine, and particularly that of females, is an excellent medium for bacterial growth, ${ }^{2}$ it is surprising that the bacteria that enter the bladder do not usually gain a foothold. That they do not is due to the effectiveness of the bladder defences.

Bacteria are washed out of the bladder by periodic voiding, and their concentration is reduced by the inflow of urine from the kidneys. The size of the population attained by organisms that enter the bladder depends on the rate of growth of the organism in the urine, the rate of urine flow, the size of the residual volume, and the frequency of micturition. The relationship between these variables has been studied in mechanical and computer models, ${ }^{34}$ and it has been shown that the clearance of organisms from the bladder in vivo far exceeds that observed in the in vitro models. ${ }^{3}$ This shows that hydrokinetic defences alone cannot account for the rapid clearance of organisms from the bladder.

The existence of a mucosal defence mechanism was first demonstrated by E. Vivaldi and his colleagues. ${ }^{5}$ They applied Escherichia coli labelled with radioactive phosphorus directly to the exposed bladder mucosa of rabbits. By the end of one hour only $0.3 \%$ of the original inoculum of $10^{6}$ organisms survived, even though the radioactivity of the mucosa persisted. They suggested that a phagocytic mechanism might account for the bactericidal effect of the bladder mucosa, the radioactive label remaining within phagocytic cells after the organisms had been killed. More recently, C. W. Norden and his colleagues ${ }^{6}$ studied the clearance of labelled organisms from the bladder of unanaesthetized guinea-pigs. More than $99.9 \%$ of the inoculum was cleared immediately after voiding; the remaining $0.1 \%$, which persisted in the film of urine which lined the "empty" bladder, was rapidly and progressively killed. Neither a phagocytic mechanism nor circulating antibodies were found to be responsible for the bactericidal effect of the bladder mucosa, and it was postulated that organic acids produced by the mucosal cells might account for the effect. Whatever the mechanism, it seems reasonable to suppose that the bactericidal effect of bladder mucosa limits the numbers of organisms multiplying in the urine, and thereby hastens their clearance by hydrokinetic mechanisms.

Hydrokinetic defences can readily be strengthened by clinicians. The residual volume can be reduced by surgical procedures, such as correction of vesico-ureteric reflux, or by advising double or even triple micturition, particularly at bedtime, since the time available for bacterial multiplication is longest during the night. For the same reason treatment of urinary tract infections should be arranged so that the urinary concentration of the antibacterial agent is adequate throughout the night. A high fluid intake also enhances hydrokinetic defences-it increases the frequency of micturition and so decreases the time available for bacterial multiplication. It also lowers the rate of bacterial multiplication, since dilute urine is a poorer culture medium. ${ }^{2}$ Furthermore, polymorphonuclear leucocytes can operate only in the isotonic or near isotonic environment provided by dilute urine. ${ }^{78}$ There is also evidence that bacterial protoplasts can survive in the hypertonic environment of the renal medulla. By reducing the hypertonicity of the renal medulla, high fluid intake leads to the destruction of bacterial protoplasts. ${ }^{9}$ The advantages of high fluid intake far outweigh the resulting dilution of antibacterial agents.

The major problem in the treatment of urinary tract infections is the frequency with which relapses and reinfections occur after initially successful treatment. ${ }^{10-12}$ Further studies of the bladder defences in subjects prone to recurrent urinary infections may bring to light specific defects of the bladder defences. This might provide the basis for a more logical approach to therapy than the present ineffective, expensive, and even dangerous habit of prescribing repeated or prolonged courses of antibacterial agents.

1 Hinman, F., jun., fournal of Urology, 1966, 96, 546.

- Asscher, A. W., Sussman, M., Waters, W. E., Davis, R. H., and Chick, S., Lancet, 1966, 2, 1037.

s Cox, C. E., and Hinman, F., jun., in Progress in Pyelonephritis, 1965, p. 563, ed. E. H. Kass. Philadelphia, F. A. Davis.

- O'Grady, F., Gauci, C. L., Watson, B. W., and Hammond, B., in Urinary Tract Infection, 1968, p. 80, ed. F. O'Grady and W. Brumfitt. London, Oxford University Press.

s Vivaldi, E., Munoz, J., Cotran, R., and Kass, E. H., in Progress in Pyelonephritis, 1965, p. 531, ed. E. H. Kass. Philadelphia, F. A. Davis.

- Norden, C. W., Green, G. M., and Kass, E. H., fournal of Clinical Investigation, 1968, 47, 2689.

"Chernew, I., and Braude, A. I., fournal of Clinical Investigation, 1962, 41, 1945.

- Brogan, T. D., Immunology, 1966, 10, 137.

- Andriole, V. T., and Epstein, F. H., fournal of Clinical Investigation, $1965,44,73$.

10 Turck, M., Browder, A. A., Lindemeyer, R. I., Brown, N. K., Anderson, K. N., and Petersdorf, R. G., New England fournal of Medicine, 1962, 267, 999.

11 Freedman, L. R., Phair, J. P., Seki, M., Hamilton, H. B., Nefzger, M. D., and Hirata, M., Yale Fournal of Biology and Medicine, 1965, 37, 262.

12 Asscher, A. W., Sussman, M., Waters, W. E., Evans, J. A. S., Campbell, H., Evans, K. T., and Williams, J. E., British Medical
fournal, 1969, 1, 804. 